\title{
Training in paediatric virology in the UK: A brief overview (Review)
}

\author{
SIMON B. DRYSDALE ${ }^{1,2}$, AISLEEN M. BENNETT ${ }^{1,2}$ and ANNE GREENOUGH GH, $^{3,4}$ \\ ${ }^{1}$ St. George's, University of London, London SW17 0RE; ${ }^{2}$ Department of Paediatric Infectious Diseases, \\ St. George's University Hospitals NHS Foundation Trust, London SW17 0QT; ${ }^{3}$ Department of Women and \\ Children's Health, School of Life Course Sciences, Faculty of Life Sciences and Medicine, King's College London, \\ London SE5 9RS; ${ }^{4}$ Asthma UK Centre in Allergic Mechanisms of Asthma, King's College London, London SE1 9RT, UK
}

Received July 31, 2020; Accepted October 24, 2020

DOI: 10.3892 /etm.2020.9420

'Today, there are different perceptions for the educational programmes. Everyone does not really have the same opinion about what young people need to learn either in the direction of virtues either in the direction of the best way of life; nor is it clear whether education must have its purpose cultivating and practicing the mind or moral ethos'

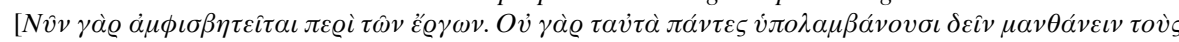

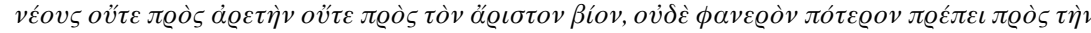

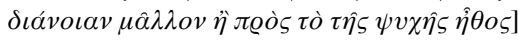

Aristotle

\begin{abstract}
Paediatric virology is a bold, new scientific field, where paediatrics focuses on the newly acquired knowledge from clinical virology, enriched with current advances in epidemiology, molecular medicine, evidence-based medicine, clinical governance, quality improvement, pharmacology and immunology. Although there are several methods with which to obtain training in paediatric viral infections in the UK, paediatric virology does not currently exist as a specific subspecialty. The aim of the present article was to present the existing educational platforms and training options in paediatric virology in the UK available to trainees wanting to pursue a clinical and/or academic career in paediatric virology.
\end{abstract}

\section{Contents}

1. Introducing paediatric virology

2. Subspecialty training in paediatric infectious diseases and immunology

3. Doctorate, masters, postgraduate diplomas and short courses

4. Other training pathways

5. Future perspectives

Correspondence to: Dr Simon B. Drysdale, Department of Paediatric Infectious Diseases, St. George's University Hospitals NHS Foundation Trust, Blackshaw Road, London SW17 0QT, UK E-mail: simon.drysdale@nhs.net

Key words: paediatric virology, paediatric training, medical education, paediatrics, subspecialties, SPIN, UK

\section{Introducing paediatric virology}

Over the past three decades, scientific advances in the field of clinical virology and molecular medicine have led to significant changes in clinical practice regarding the management and treatment of neonates and children with viral infections. These advances have highlighted the role of paediatric virology as a new unique challenging scientific area, where paediatric professionals of the 21 st century will require enhanced state-of-the-art education. The new challenges related to the rapidly evolving world of paediatric viral infections include new emerging infections (e.g., SARS-CoV-2, Zika virus), re-emerging infections (e.g., Ebola virus), opportunistic infections in immunocompromised patients (e.g., CMV), the development of new and improved antivirals and vaccines, antimicrobial resistance and the development of improved diagnostic tests. In most countries, children with viral infections are usually managed by general paediatricians or paediatric infectious disease (PID) subspecialists assisted by microbiologists or clinical virologists. Recently, paediatric virology was proposed as a separate candidate for paediatric subspecialisation (1), while different educational pathways on paediatric virology were presented by Mammas et al (2). The aim of the present article was to review current practices in the UK giving examples of the existing educational platforms and training options in paediatric virology, which currently are offered to paediatric trainees wanting to pursue a career in paediatric virology.

\section{Subspecialty training in paediatric infectious diseases} and immunology

Training to become a consultant paediatrician in the UK, currently, takes 8 years - specialty training (ST) years 1-8 (3). To become a subspecialist in paediatric infectious diseases - it 
Table I. Example of short courses available across the UK on platforms including face-to-face, online with or without tutoring and MOOC on paediatric infections including virology.

\begin{tabular}{|c|c|c|}
\hline Course title & Course provider & Type of course \\
\hline Virology: Fundamental Laboratory Techniques and Practices & Public Health England & Face to face \\
\hline COVID-19: Tackling the Novel Coronavirus & $\begin{array}{l}\text { London School of Hygiene } \\
\text { and Tropical Medicine }\end{array}$ & MOOC \\
\hline $\begin{array}{l}\text { Ebola in context: Understanding transmission, } \\
\text { Response and Control }\end{array}$ & $\begin{array}{l}\text { London School of Hygiene } \\
\text { and Tropical medicine }\end{array}$ & Free online course \\
\hline Infectious diseases and host defence & Imperial College London & Face to face and online \\
\hline Hazards in Travel Health & $\begin{array}{l}\text { Liverpool School of } \\
\text { Tropical Medicine }\end{array}$ & Online course \\
\hline $\begin{array}{l}\text { Preventing the Zika Virus: Understanding and Controlling } \\
\text { the Aedes Mosquito }\end{array}$ & FutureLearn & MOOC \\
\hline Maternal Infections & $\begin{array}{l}\text { Oxford Maternal and Perinatal } \\
\text { Health Institute (OMPHI) }\end{array}$ & Free online course \\
\hline
\end{tabular}

MOOC, massive online open courses.

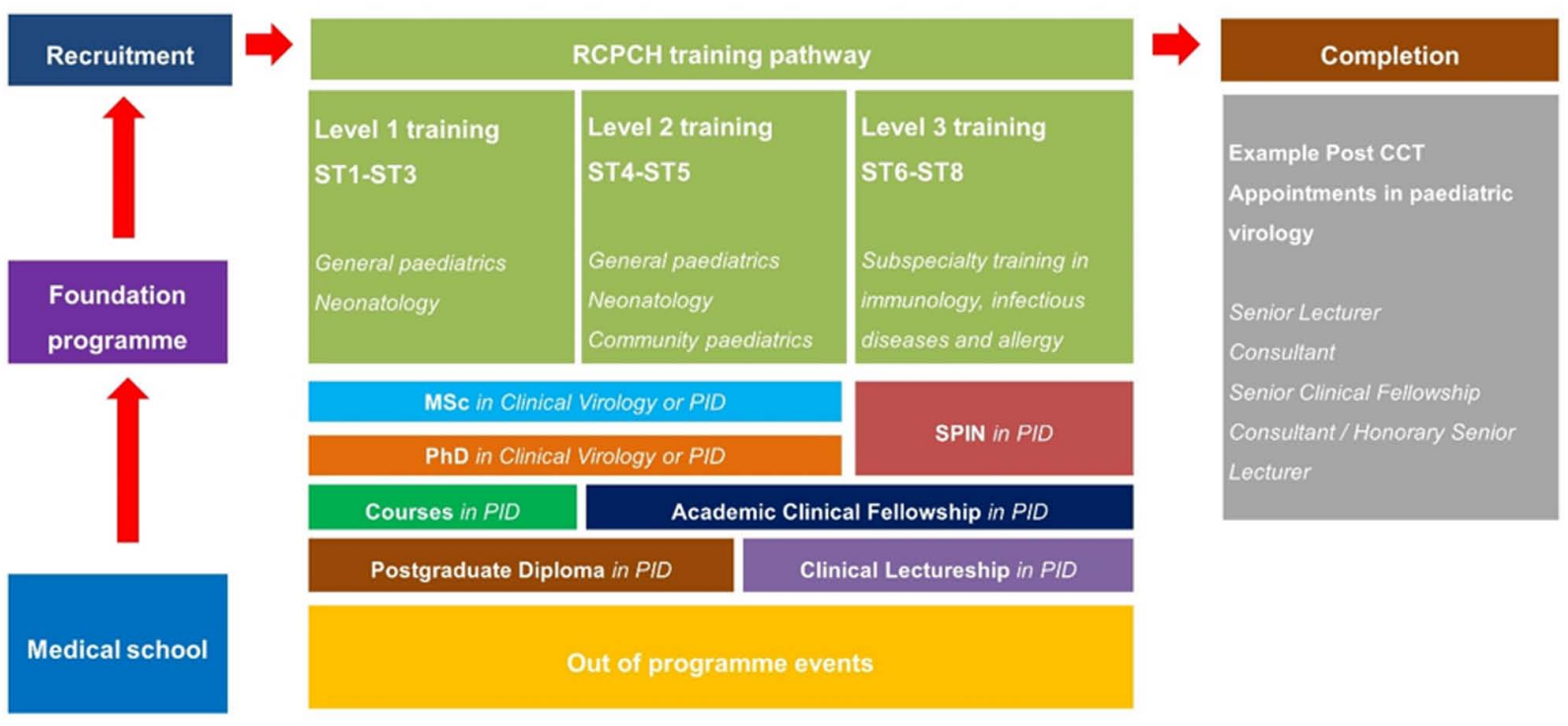

Figure 1. Current RCPCH training pathway in paediatric virology in the UK. RCPCH, Royal College of Paediatrics and Child Health; ST, specialty training; MSc, Master of Sciences; PhD, Doctor of Philosophy; SPIN, specialist interest; CCT, certificate of completion of training; PID, paediatric infectious diseases.

is currently not possible to become a subspecialist in paediatric virology alone - a trainee must usually apply to enter the subspecialty training programme ('grid training') in ST5 or ST6 to start in ST6 or ST7 (4). Trainees, therefore, undertake 2 or 3 years of subspecialty training and ultimately will enter the Specialist Register with the General Medical Council (GMC) as a consultant paediatrician with a subspecialty interest in infectious diseases. For those who do not wish to become subspecialists but wish to develop further skills in a particular subspecialty there is the opportunity to undertake a specialist interest (SPIN) module (5). SPIN modules allow trainees to undertake additional training and gain experience in a specific area of paediatrics. The curriculum for the paediatric infectious diseases SPIN module is currently under review. At present neither PID Grid training nor the PID SPIN module allow for training in paediatric virology as a separate subspecialty (Fig. 1).

It is also possible to undertake training in adult medicine and subspecialise as a medical virologist (6). It is then possible to advise on the diagnosis and management of viral infections in children although not work as a paediatrician unless training in paediatrics is also undertaken.

\section{Doctorate, Masters, Postgraduate diploma and Short courses}

Another pathway to gain knowledge and experience in paediatric viral infections is to undertake a higher degree, diploma 
or short course on the topic. There are a number of Doctorate (e.g., PhD or MD) or Masters (e.g., MSc) programmes run by various institutions in the UK which paediatric trainees can apply for. Examples of UK institutions that regularly fund Doctoral or Masters students include the Wellcome Trust (https://wellcome.ac.uk/), the Medical Research Council (MRC) (https://mrc.ukri.org/) and the National Institute for Health Research (NIHR) (https://www.nihr.ac.uk/). Each of these allows applications on many topics of medical research including viral infections in children which can be undertaken in the UK or abroad. Occasionally there are specific calls on topics related to infections in children. Most UK universities also have regular or ad hoc Doctorate or Masters posts than can be applied to.

The University of Oxford's postgraduate diploma in paediatric infectious diseases (PgDip PID) (7) and MSc in paediatric infectious diseases (8) are well-established UK courses for paediatricians and other specialists with an interest in paediatric infectious diseases. The PgDip PID covers a wide range of topics including viral infections, such as congenital infections, viral exanthem, respiratory viruses and HIV. The PENTA Tr@inforPedHIV course (9) is undertaken as part of the diploma. The MSc is open to students who have completed the PgDip PID and can be undertaken on any topic of paediatric infection including viral infections.

In addition, there are many short courses available across the UK on platforms including face-to-face, online with or without tutoring and massive online open courses (MOOC) on paediatric infections including virology (Table I).

\section{Other training pathways}

It is possible to train in paediatric infectious diseases outside the UK, either undertaking time out of programme from the UK paediatrics training programme or training abroad and then applying to enter the UK training programme or applying directly for a consultant post. For those taking time out of the programme for clinical training, this is often done as a clinical fellowship (commonly 1-2 years). In theory, this can be done in any country; however, Canada and Australia are common places for UK paediatricians to go to due to their well-established paediatric infectious diseases training programmes and the relative ease with which UK doctors can obtain medical registration, work visas, etc. (e.g., compared with the USA where USMLE exams need to be completed prior to being able to work there). The time out of the programme has to be approved by the appropriate UK authorities (e.g., local paediatric deanery).

\section{Future perspectives}

An in-depth knowledge of paediatric virology is essential for paediatricians with an interest in infectious diseases. There are several avenues to obtain training on paediatric virology although it does not currently exist as a specific subspecialty in the UK. In light of recent epidemics/pandemics of viral infections and an increased understanding of the pathophysiology of viral infections in children, it remains to be seen whether there will become a need for paediatric virology to become a new, separate paediatric subspecialty. The future contribution of the newly founded Institute of Paediatric Virology in this direction is essential.

\section{Acknowledgements}

This article is published in the context of the foundation of the Institute of Paediatric Virology (IPV; https:// paediatricvirology.org) based on the island of Euboea (Greece), under the auspices of the World Academy of Sciences (WAS) and the support of the Department of Clinical Virology of the University of Crete School of Medicine and the First Department of Paediatrics of the University of Athens School of Medicine. We would like to thank all the members of the IPV for their valuable comments and corrections.

\section{Funding}

No funding was received.

\section{Availability of data and materials}

Not applicable.

\section{Authors' contributions}

All authors (SBD, AMB and AG) contributed to the conception and design of this manuscript, wrote the original draft, edited and critically revised the manuscript, read and approved the final manuscript.

\section{Ethics approval and consent to participate}

Not applicable.

\section{Patient consent for publication}

Not applicable.

\section{Competing interests}

SBD is a consultant paediatrician and subspecialist in paediatric infectious diseases and immunology, lectures and examines on the University of Oxford's PgDip PID and MSc courses, and is a Member of the Advisory Academic Board (AAB) of the Institute of Paediatric Virology (IPV). AMB declares that she has no competing interests. AG is Chair of the Advisory Academic Board (AAB) of the IPV.

\section{References}

1. Mammas IN, Greenough A, Theodoridou M and Spandidos DA: Paediatric Virology: A new paediatric subspecialty? A proposal at the Workshop on Paediatric Virology, Athens, October 10, 2015. Exp Ther Med 11: 3-5, 2016.

2. Mammas IN, Greenough A, Theodoridou M and Spandidos DA: Educational pathways in Paediatric Virology: Pros and cons. Exp Ther Med 18: 3260-3262, 2019.

3. Royal College of Paediatrics and Child Health ( $\mathrm{RCPCH})$ : Current training pathway. RCPCH, 2020. https://www.rcpch. ac.uk/resources/training-guide\#current-training-pathway. Last Updated September 8, 2020. 
4. Royal College of Paediatrics and Child Health (RCPCH): Sub-specialty training(GRID).RCPCH, 2020.https://www.rcpch. ac.uk/resources/training-guide\#sub-specialty-training-grid. Last Updated September 8, 2020.

5. Royal College of Paediatrics and Child Health $(\mathrm{RCPCH})$ : Special interests (SPIN) modules. RCPCH, 2020. https://www.rcpch. ac.uk/resources/training-guide\#special-interests-spin-modules. Last Updated September 8, 2020.

6. The Royal College of Pathologists: Training in Virology. RCPath, 2020. https://www.rcpath.org/discover-pathology/ careers-in-pathology/train-to-work-in-pathology/training-invirology.html.

7. University of Oxford: PGDip in Paediatric Infectious Diseases. University of Oxford, 2020. https://www.ox.ac.uk/admissions/ graduate/courses/pgdip-paediatric-infectious-diseases?wssl=1). Last Updated September 1, 2020.
8. University of Oxford: MSc in Paediatric Infectious Diseases. University of Oxford, 2020. https://www.ox.ac.uk/admissions/ graduate/courses/msc-paediatric-infectious-diseases?wssl=1. Last Updated September 1, 2020.

9. Penta: Training and education. Penta, 2020. https://penta-id.org/ education/trainforpedhiv/\#: :text=It $\% 20$ is $\% 20 \mathrm{a} \% 20$ training $\% 20$ programme,learning $\% 20$ with $\% 20$ interactive $\% 20$ residential $\% 20$ courses

This work is licensed under a Creative Commons Attribution-NonCommercial-NoDerivatives 4.0 International (CC BY-NC-ND 4.0) License. 